\title{
Prevalence and risk factors of erectile dysfunction in Niger delta region, Nigeria
}

\author{
Idung $\mathrm{AU}^{1}$, *Abasiubong $\mathrm{F}^{2}$, Ukott IA ${ }^{1}$, Udoh $\mathrm{SB}^{1}$, Unadike $\mathrm{BC}^{3}$ \\ 1. Departments of Family Medicine ${ }^{1}$, Faculty of Clinical Sciences, College of Health Sciences, University, of Uyo, Akwa \\ Ibom State, Nigeria \\ 2. Departments of Psychiatry, Faculty of Clinical Sciences, College of Health Sciences, University, of Uyo, Akwa Ibom State, \\ Nigeria \\ 3. Departments of Internal Medicine, Faculty of Clinical Sciences, College of Health Sciences, University, of Uyo, Akwa \\ Ibom State, Nigeria
}

\begin{abstract}
Background: Erectile Dysfunction (ED) is one of the major social problems causing significant distress in men. Despite the increasing difficulty in management, knowledge, and understanding of factors responsible for its development are important for prevention and care.

Objectives: To assess the prevalence and risk factors for ED among men in Niger Delta Region of Nigeria, in order to determine its contextual variables.

Methods: Subjects included 400 male patients attending the general outpatients' clinic (GOPC) of the University of Uyo Teaching Hospital. Respondents completed the abridged version of the International Index of Erectile Function (IIEF-5).

Results: A total of 166 (41.5\%) subjects had ED; 66 (16.5\%) had mild; $32(8.0 \%)$ mild to moderate; $24(6.0 \%)$ moderate; while $45(11.3 \%)$ had severe $37(9.2 \%)$ resulted from hypertension and its medications; $29(7.3 \%)$ from diabetes; $49(12.2 \%)$ from a combination of both and their therapies ( $\mathrm{P}=0.044) ; 24(6.0 \%)$ had history of previous surgery; while for $27(6.8 \%)$ it was from undiagnosed medical conditions $(\mathrm{p}=0.001)$. The ED increases with age and is more among married and educated men.

Conclusion: ED is a common problem among men in Niger Delta region. Therefore, efforts must be made to reduce the incidence by dealing with the factors responsible for its development.
\end{abstract}

Key words: erectile dysfunction, men, distress, Niger delta region, Nigeria

African Health Sciences 2012; 12(2): 160 - 165 http://dx.doi.org/10.4314/ahs.v12i2.13

\section{Introduction}

Erectile dysfunction (ED) is currently one of the most common sexual dysfunctions in men worldwide ${ }^{1}$. This serious health problem has been the focus of public attention in recent times. It ranges from partial decrease in penile rigidity to a complete erectile failure $^{2}$. The National Institutes of Health (NIH) defines it as the consistent inability to maintain a penile erection, sufficiently for satisfactory sexual intercourse ${ }^{3}$.

The estimated global prevalence has been on the increase. It is projected that the number of men with this condition will rise to 322 million by

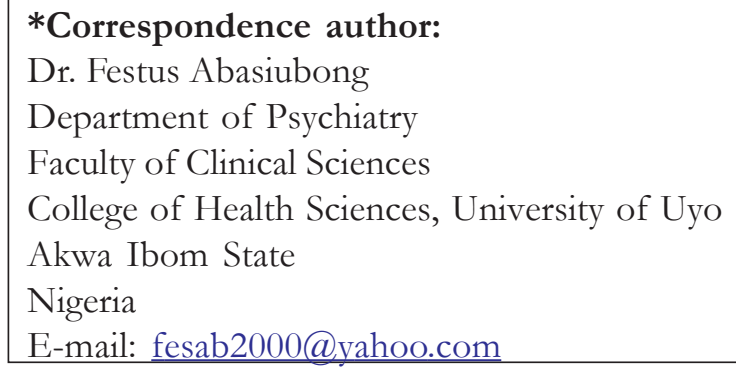

the year $2025^{4}$. Erectile dysfunction is usually underestimated in many developing countries including Nigeria, 6,7. This is because it is not a life threatening condition and due to associated stigma, men with the problem rarely seek help. There is also the problem of early detection and management of factors responsible for the development of erectile dysfunction. The impact of ED could be devastating because evidence has shown that sexual function is one of the important indices of quality of life ${ }^{8,9,10}$. The dysfunction could affect all levels of intimacy, like emotional, social, sexual, recreational and intellectual intimacy ${ }^{10}$. Previous studies have reported significant poor health-related quality of life (HRQOL) in men with $\mathrm{ED}^{12}$. This has been found to affect both general and disease-specific healthrelated quality of life (HRQOL). Therefore, there is need to address this social health problem.

The causes of ED until recently, were mainly thought to be due to psychogenic factors. However,

African Health Sciences Vol 12 No 2 June 2012 
various studies have shown that the causes of ED may be multifactorial ${ }^{11,12,13}$. Organic factors such as chronic medical conditions including hypertension, diabetes mellitus, as well as adverse effects of therapies used for these conditions are known to constitute major causes of $\mathrm{ED}^{6,14,15,16}$. Evidence suggests that there is a strong association between age and $\mathrm{ED}^{14,17,18}$. This is because cardiovascular risk factors are associated with increasing age, and since penile erection is primarily a vascular event, it may be impaired in conditions in which degenerative changes result in endothelial dysfunction ${ }^{5,7}$. Furthermore, the physiological alterations related to hormonal changes and sedentary lifestyle have been implicated in the causes of $\mathrm{ED}^{14.19}$. It is also reported that psychological problems such as depression, performance anxiety, and relationship problems could be both complications and risk factors of $\mathrm{ED}^{12,13,2021}$.

In the Niger Delta region of Nigeria with limited and deplorable healthcare services, the high level of poverty and ignorance in the region suggest that men with this problem may not have access to adequate care. Therefore, it is important to take cognizance of the various adverse health conditions that probably contribute to its development. This study attempts to add to the pool of information currently available from the developing world on the prevalence and risk factors of ED. It is hoped that the findings would increase awareness amongst men with ED and enhance positive attitude to care.

\section{Methods \\ Study area}

This study was carried out at the University of Uyo Teaching Hospital located on the outskirts of Uyo, the capital of Akwa Ibom State. The State is situated in the South-South geopolitical zone of Nigeria, and is one of the major oil producing areas in Niger Delta region. The hospital is the only tertiary and referral health institution in the State and its environs serving a population of more than 3.9 million people.

\section{Data collection}

Between January and March 2009, a sample of 400 male patients, aged between 20 and 70 years old and attending the general out-patient clinic (GOPC) of the University of Uyo Teaching Hospital for medical problems were assessed for erectile dysfunction. A systematic random sampling method was used to recruit the subjects into the study. Every $7^{\text {th }}$ man who attended the clinic on each clinic day throughout the period of the study was recruited. The number seven was derived by dividing the study population by the sample size calculated, using the formula, $\mathrm{N}=\mathrm{z}^{2} \mathrm{pq} / \mathrm{d}^{2}$. This was rounded up to 400 at the end. They completed the abridged version of the International Index of Erectile (IIEF-5) Function $^{22}$, after informed consent had been obtained from each of the participants. A sociodemographic questionnaire was used to elicit information on sociodemographic characteristics. The IIEF-5 is a brief, reliable and valid self-administered questionnaire containing five domains. It has been used widely in many countries including Nigeria to detect the presence and severity of $\mathrm{ED}^{13,23,24}$. The erectile function was classified based on the scores on IIEF into severe $0-7$; moderate $8-11$; mild to moderate 12-16; 17-21, mild (17-31) ED and 2225 , no dysfunction. This study passed through the ethical and research committee of the hospital for approval.

\section{Data analysis}

The results of the study were analyzed using the Statistical Package for Social Sciences (SPSS 17.0). Comparisons of categorical data were done using the chi-square test. The p-value of equal to or less than 0.05 was used to determine the level of statistical significance.

\section{Results}

Of the 400 participants recruited into the study, 71 $(17.7 \%)$ were aged below 29 years; $115(28.7 \%)$ between 30 and 49 years; $160(40.0 \%)$ between 50 and 69 years; while 54 (13.5) were aged 70 years and above. Table 1 shows the socio-demographic characteristics of the respondents. Two hundred and fifty nine $(64.8 \%)$ respondents were married; 121(30.3\%) were single; $8(2.0 \%)$ were co-habiting; while $12(3.0 \%)$ were either separated or divorced. A total of $300(75.0 \%)$ had at least secondary education; while $96(24.0 \%)$ had primary school education and $4(1.0 \%)$ had no formal education. One hundred and sixty seven (44.8\%) respondents were professionals, $129(32.3 \%)$ and $61(15.3 \%)$ were unskilled and skilled workers respectively; while 87 $(21.8 \%)$ were unemployed. A total of 231 (57.8\%) participants resided in urban areas; while 169 (42.2\%) lived in the rural areas. 
Table 1: Socio-demographic characteristics of the respondents and erectile dysfunction

\begin{tabular}{|c|c|c|c|c|}
\hline \multirow[t]{2}{*}{ Variables } & \multicolumn{2}{|c|}{ Subjects } & \multirow[b]{2}{*}{$\mathbf{X}^{2}$} & \multirow[b]{2}{*}{ P-value } \\
\hline & $\begin{array}{l}\text { With ED } \\
\text { n }(\%)\end{array}$ & $\begin{array}{l}\text { Without ED } \\
\text { n (\%) }\end{array}$ & & \\
\hline \multicolumn{5}{|l|}{ Age in years } \\
\hline$<29$ & - & $71(17.8)$ & 233.99 & $0.001 *$ \\
\hline $30-49$ & $13(3.2)$ & $102(25.5)$ & & \\
\hline $50-69$ & $101(25.3)$ & $59(14.8)$ & & \\
\hline$>70$ & $52(13.0)$ & $2(0.5)$ & & \\
\hline \multicolumn{5}{|l|}{ Marital status } \\
\hline Single & $19(4.7)$ & $102(25.5)$ & 168.63 & $0.001 *$ \\
\hline Married & $137(34.3)$ & $122(30.5)$ & & \\
\hline Cohabiting & - & $8(2.0)$ & & \\
\hline Sep/Divorced & $10(2.5)$ & $2(0.5)$ & & \\
\hline \multicolumn{5}{|c|}{ Educational Level } \\
\hline NFE & $1(0.2)$ & $3(0.8)$ & 22.66 & $0.001 *$ \\
\hline Prim Sch & $59(14.8)$ & $37(9.2)$ & & \\
\hline Sec. Sch & $43(10.7)$ & $63(15.8)$ & & \\
\hline Post Sec Sch & $63(15.8)$ & $131(32.7)$ & & \\
\hline \multicolumn{5}{|l|}{ Occupation } \\
\hline Unemployed & $51(12.8)$ & $36(9.0)$ & 52.05 & $0.001 *$ \\
\hline Unskilled & $32(8.0)$ & $97(24.3)$ & & \\
\hline Skilled & $39(9.8)$ & $22(5.5)$ & & \\
\hline Professional & $44(11.0)$ & $123(30.8)$ & & \\
\hline \multicolumn{5}{|l|}{ Residence } \\
\hline Rural & $88(22.0)$ & $81(20.3)$ & 12.73 & $0.001 *$ \\
\hline Urban & $78(19.5)$ & $153(38.3)$ & & \\
\hline
\end{tabular}

*Statistically significant $\quad$ Prim sch=Primary school $\quad$ Sec sch= Secondary school

Post sec sch=Post secondary school With ED=With erectile dysfunction Without ED=Without erectile dysfunction

Table 2 shows the distribution of various health conditions associated with ED among the respondents. Of the 400 patients seen in the clinic during the period, $166(41.5 \%)$ had ED, and 234 $(58.5 \%)$ had no dysfunction. Thirty seven $(9.2 \%)$ of the 166 respondents with ED suffered from hypertension and were on medications; 29 (7.3\%)

suffered from diabetes and were on medications; $49(12.2 \%)$ from a combination of hypertension and diabetes mellitus and were on their medications $(\mathrm{p}=0.044) ; 24(6.0 \%)$ were previously operated upon; while $27(6.8 \%)$ suffered from undiagnosed medical conditions and were reportedly on complimentary/ alternative medications $(\mathrm{p}=0.001)$.

Table 2: Various health conditions and erectile dysfunctions among respondents

\begin{tabular}{llllll}
\hline Health conditions & With ED & $\begin{array}{c}\text { Subjects } \\
\text { Without ED }\end{array}$ & \multirow{2}{*}{$\mathbf{X}^{2}$} & P-value \\
\cline { 2 - 3 } & $\mathbf{n ~ ( \% )}$ & $\mathbf{n ~ ( \% )}$ & & \\
\hline Htn \& anti-htn & $37(9.2)$ & $64(16.0)$ & & 1.83 & 0.067 \\
Diab \& anti-diabs & $29(7.3)$ & $57(14.3)$ & & 2.01 & $0.044^{*}$ \\
Comb. of medicines & $49(12.2)$ & $72(18.0)$ & 1.44 & 0.151 \\
Previous surgeries & $24(6.0)$ & $41(10.2)$ & & 1.31 & 0.192 \\
Undiag cond. \& Cam & $27(6.8)$ & - & 3.74 & $0.001^{*}$ \\
Total & $\mathbf{1 6 6 ( 4 1 . 5 )}$ & $\mathbf{2 3 4}(\mathbf{5 8 . 5 )}$ & & \\
\hline
\end{tabular}

*Statistically significant $\quad$ Htn \& anti-htns $=$ Hyperypertension and antihypertensive medications Diab \& anti-diabs=Diabetes and anti-diabetic medications Comb. of both \& med $=$ Combination of hypertension and Diabetes Mellitus Undiag cond \& cam= undiagnosed condition and complementary and alternative medicine 
Table 3 shows the degree of ED among the respondents with relation to the health conditions. A total of 15 (3.7\%) of ED resulting from hypertension and its medications were mild; $11(2.8 \%)$ mildmoderate; $4(1.0 \%)$ and $7(1.7 \%)$ were moderate and severe respectively. Similarly, $6(1.5 \%)$ of ED resulting from diabetes and its medications were mild; $5(1.3 \%)$ mild-moderate; $7(2.8 \%)$ moderate; while $11(2.8 \%)$ were severe. Of the $49(12.2 \%)$ of ED that resulted from a combination of hypertension and diabetes and their medications, 21 (5.2\%) were mild; $3(0.8 \%)$ mild-moderate; $8(2.0 \%)$ moderate; while $17(4.3 \%)$ were severe. Previous surgeries contributed to $24(6.0 \%)$ of ED, of which $9(2.3 \%)$ were mild; $691.5 \%$ ) mild-moderate; while 10 (2.5\%) were severe. The majority $15(3.7 \%)$ of ED resulting from undiagnosed medical conditions and complementary and alternative medications were mild; $7(1.7 \%)$ mild-moderate, while $5(1.3 \%)$ were moderate.

Table 3: Distribution of health conditions and degree of sexual dysfunction among respondents

\begin{tabular}{|c|c|c|c|c|}
\hline \multirow[t]{2}{*}{ Health Conditions } & \multicolumn{3}{|c|}{ Degree of erectile dysfunction } & \multirow[b]{2}{*}{ Severen $(\%)$} \\
\hline & $\begin{array}{l}\text { Mild } \\
\text { n (\%) }\end{array}$ & $\begin{array}{l}\text { Mild-Moderate } \\
\text { n }(\%)\end{array}$ & $\begin{array}{l}\text { Moderate } \\
\text { n (\%) }\end{array}$ & \\
\hline Htn \& anti-htn & $15(3.7)$ & $11(2.8)$ & $4(1.0)$ & $7(1.7)$ \\
\hline Diab \& anti-diabs & $6(1.5)$ & $5(1.3)$ & $7(1.7)$ & $11(2.8)$ \\
\hline Comb. of medicines & $21(5.2)$ & $3(0.8)$ & $8(2.0)$ & $17(4.3)$ \\
\hline Previous surgeries & $8(2.0)$ & $6(1.5)$ & - & $10(2.5)$ \\
\hline Undiag cond. \& Cam & $15(3.7)$ & $7(1.7)$ & $5(1.3)$ & - \\
\hline Total & $65(16.2)$ & $32(8.0)$ & $24(6.0)$ & $45(11.3)$ \\
\hline
\end{tabular}

Mild-Mod=mild to moderate

\section{Discussion}

The findings of this study show that ED is common in our environment. The findings are similar to the reports in previous studies ${ }^{5,18,19,25,26}$. Although, the rate of $41.5 \%$ found in this study is lower compared to the findings in previous studies, this is significant in view of the fact that men with ED do not always confide in other people or readily seek medical attention. Considering the limited healthcare facilities and poor services in Niger Delta region of Nigeria, the present rate seems to suggest that there is a problem. Therefore, efforts must be made to improve our healthcare services, so as to be able to detect and intervene early in some of the treatable medical conditions responsible for ED.

In line with the reports in previous studies, our findings have shown that erectile dysfunction was more in men who were older ${ }^{2,5,25,26}$. Several reasons including changes in the testicles and agerelated decline in male sex hormones have been adduced for the increasing incidence of ED in older men. The degenerative and the fact that older men are known to be more worried about sexual performance are some of the other factors commonly associated with $\mathrm{ED}^{14,15}$. In our study, erectile dysfunction was also found in $60 \%$ of married and $45 \%$ of educated men. The high incidence in married men may be attributable to the frequency of sexual activity. This in turn may be due to the cultural expectation on procreation in marriage. These findings may seem to suggest that married men are more sexually active and more prone to ED than the unmarried ones. However, the fact that there is also a significant proportion of ED among men who are not married in this study shows that the problem is multifactorial in nature. There is no proof to demonstrate that married men indulge in more sexual activities than the unmarried ones. On the other hand, education is a major determinant of social class, and could influence the lifestyle of individuals. Although there have been divergent opinions on the impact of socioeconomic factors on sexual functions, individuals in a higher socio-economic class are more prone to stress. This is because of their status and lifestyles, which have the tendency to predispose them to cardiovascular risk factors ${ }^{19,27}$.

Significantly, our study also shows a high frequency of erectile dysfunction among respondents who were either separated or divorced. This is not surprising and life events could be a possibility. The loss of self-esteem, decreased libido and erectile dysfunction could be due to pressure and frustration in relationships. In addition to adverse lifestyle, this 
could predispose respondents to major psychological distress including depression $\sin ^{7,13,20,21}$. There is increasing evidence that emotional and relationship problems could be both the complications and risk factors of $\mathrm{ED}^{12,13,2021}$.

Although the present study did not focus specifically on alcohol abuse/dependence, it is a well known fact that alcohol and other substance use including smoking are the major risk factors of $\mathrm{ED}^{18}$. It may be interesting to note that in Niger Delta region, alcohol in the form of palmwine, local gin and liquor is a locally produced substance with long historical and traditional importance ${ }^{28}$. Therefore, its use in various ceremonies / celebrations such as traditional marriages, and naming ceremonies is not restricted. This is common among both low and higher socio-economic classes, and could account for the high incidence of ED in educated and unemployed men.

The findings of this study also highlight the risk factors for ED in our environment. In line with previous studies, our study shows that hypertension and diabetes with their medications are still the major risk factors of ED. This strongly corroborates the findings in earlier studies ${ }^{18,25,26,29}$. Although it is reported that sexual dysfunction in males with hypertension presents in a variety of ways, it has been found that the problem tends to occur more frequently in patients receiving antihypertensive medications ${ }^{15,30}$. There is also increasing evidence that $\mathrm{ED}$ is three times greater in patients treated for diabetes $^{31}$. The association between medications and $\mathrm{ED}$ is confounded by the underlying medical conditions and the drug-related effect is difficult to distinguish from the effect of the diseases ${ }^{16}$. Therefore, it may not be unreasonable to argue that the control of these medical conditions could reduce significantly the incidence of erectile dysfunction in our environment.

We also found that $6.8 \%$ of erectile dysfunction in this study was due to undiagnosed medical conditions and complementary and/or alternative medications. This is an indication that ED is multifactorial in nature. Although ED is known to have a strong organic component, it has been found that erectile dysfunction could be due to psychogenic factors especially in men less than 35 years of age ${ }^{11,12}$. Studies have also shown that $10 \%$ of ED in men above 50 years is psychogenic in origin. It has also been reported that men with organic ED could as well develop a psychogenic component ${ }^{12}$. The use of complementary/alternative medications to treat
ED in our environment may not be unconnected with the social stigma, cultural perception on aetiology and the perceived response to indigenous herbs. Our study also demonstrates that previous surgical exposures were associated with ED in men. The implication is that extreme care must be taken during surgical procedures to prevent unnecessary health hazards.

The limitations of this study are that it is a hospital-based study and the results cannot be generalized. Furthermore, it is a self-report and because of the stigma, the responses are bound to be biased.

\section{Conclusion}

The results of this study have shown that ED is common in our environment. Therefore, there is a need to upgrade and improve the existing healthcare facilities, in order to deal with factors responsible for its development. Health education on lifestyle modification is also important and can help primarily in reducing the cardiovascular components of the risk factors. There is also a need for public enlightenment campaigns to reduce stigma and increase awareness on the causes of ED. This will help in discouraging cultural and traditional approaches to management of erectile dysfunction in our environment.

\section{References}

1. Ariba AJ, Oladopo OT, Iyaniwura CA, Dada OA. Management of erectile of dysfunction: Perception and practices of Nigerian Primary care clinicians. SA Fam Pract. 2007; 49 (9): 1629.

2. Piores OM, Jimeno CA, Acampado LT. Erectile Dysfunction Among Diabetes Men At UP-PGH Outpatient Department: Prevalence And Risk Factors. Phil. J Internal Medicine. 2004; 42: 197 202.

3. National Institutes of Health (NIH) Consensus Development Panel on Impotence JAMA, 1993 Conference, 26:83.

4. Aytac IA, Mckinlay B, Krane RJ. The likely worldwide increase in erectile dysfunction between 1995 and 2025 and some possible policy consequences. BJU International. 1999; 84:50-56.

5. Berrada S, Kadiri N, Mechakra-Tahiri S, Nejjari C. Prevalence of erectile dysfunction and its correlates: a population- based study in Morrocco. Int. J of Impot Res. 2003; 15(suppl1): S 3-7. African Health Sciences Vol 12 No 2 June 2012 
6. Olarinoye JK, Kuranga SA, Katibi IA, Adeniran OS, Jimoh AAG, Sanya EO. Prevalence and determinants of erectile dysfunction among people with type 2 Diabetes in Ilorin Nigeria. The Nigeria Postgraduate Medical Journal. 2006; 13(4): 291-296.

7. Quek F, Sallam AA, Ng CH, Chua CB. Prevalence of sexual problems and its association with social, psychological and physical factors among men in a Malaysian population: A cross- sectional Study. J. Sex Med. 2008; 5:70-6.

8. McCabe MP. (1997). Intimacy and Quality of Life Among Sexually Dysfunctional Men and Women. Journal of Sex \& Marital Therapy 1997; 23 (4):276290.

9. Abolfoutouh M \& AL Helali NS (2001). Effect of erectile dysfunction on quantity of Life. East Mediterranean Health Journal. 2001; 7 (3): 510-518.

10. Althof SE. Quality of Life and Erectile dysfunction. Urology.2002; 59:803-810.

11. Rosen RC. Psychogenic erectile dysfunction. Classification and management. Urol. Clin North Am. 2001; 28: 269-78.

12. Usta MF, Erdogru T, Tefekli A, Koksa, T, Yucel B, \& Kadioglu A. Honeymoon impotence: psychogenic or organic in origin? Urology. 2001; 57:758-62.

13. Okulate G, Olayinka O, Dogunro AS. Erectile dysfunction and relationship to depression alcohol abuse and panic disorders. General Hospital Psychiatry. 2003; 25 (3); 209-213

14. Shabsigh $\mathrm{R} \&$ \& Anastaiadis AG. Erectile Dysfunction. Annu. Rev Med. 2003; 54: (153-68.

15. Garko B, Ogunsina MO, Danbauchi SS. Sexual dysfunction in hypertensive patients. Implications for therapy. Ann Afr med.2005; 4:46-51.

16. Naya Y, Mizutani Y, Ochiai A, Soh J, Kawauchi A, Fujito A et al. Preliminary report of association of chronic diseases and erectile dysfunction in middle-aged men in Japan. Urology 2003: 65:532536.

17. Fatusi AO, IJadunola KT, OJofeitimi EO, Adeyemi MO, Adewuyi AA. Assessment of Andropuase Awareness and Erectile Dysfunction among married men in Ile lfe Nigeria. Aging. 2003; 6(2): 79-85

18. Shaeer KZM, Osegbe DN, Siddiqui SH, Razzague A, Glasser DB, Jaguste V. Prevalence of erectile dysfunction and its correlates among men attending primary care clinics in three countries: Pakistan, Egypt and Nigeria. Int. I Impot Research. 2003; supp. 8-14.

19. Billups KL, Bank AJ, Padma-Nathan H, Katz SD \& Williams RA. Erectile dysfunction as a harbinger for increased cardiometabolic risk. Int. I Impot Research. 2008; 20: 236-242.

20. Araujo AB, Durante R, Feldman HA, Goldstein I \& McKinlay JB. The relationship between depressive symptoms and male erectile dysfunction: cross-sectional results from the Massachusetts Male Aging Study. Psychosomatic Med. 1998; 60: 458-65.

21. Seidman SN, Roose SP, Menza MA, Shabsigh R \& Rosen RC. Treatment of erectile dysfunction in men with depressive symptoms: results of a placebo-controlled trial with sidennafil citrate. Am J Psychiatry. 2001; 158: 1623-30.

22. Rosen RC, Cappelleri JC, Smith MD, Lipsky J \& Pena BM. (1999). Development and evaluation of an abridged, 5-item version of the International Index of Erectile Function (IIEF5) as a diagnostic tool for erectile dysfunction. Int. I Impot Res. 1999; 11:319.

23. Rhoden EL, Telokan C, Sogari PR, Vargas Souto CA. The use of the simplified international index of erectile function (IIEF-5) as a diagnostic tool to Study the prevalence of erectile dysfunction. Int. I Impot Res. 2002; 14: 245-250.

24. Unadike BC, Eregie A \& Ohwovoviole AE. Prevalence and Types of Sexual dysfunction amongst males with Diabetes in Nigeria. African Journal of Diabetes Medicine. 2008; 18-20.

25. Moreira ED, Bestance WJ, Bartolo EB, \& Fittipaldi JA. Prevalence and determinants of erectile dysfunction in Santos, South eastern Brazil. Sau Paulo med. Journal. 2002; 120:49-54.

26. Seyam R, Albarky A, Ghobish A, Arif H, Dandash $\mathrm{K}$ \& Rashwan H. Prevalence of erectile dysfunction and its correlates in Egypt: a community based study. Int. I Impot. Res. 2003; 15:237-245.

27. Pinnock CB, Stapleton AM, Marshall VR. Erectile dysfunction in the Community: a prevalence Study. Med J. 1999; 171: 353-357.

28. Omigbodun OO \& Babalola. Psychosocial dynamics of psychoactive substance misuse among Nigerian Adolescents. Annals of African Medicine.2004; 3 (3):111-115.

29. SafarineJad MR. Prevalence and Risk factors for erectile dysfunction in a population-based study in Iran. Int. J Impot Res. 2003; 15:246-252.

30. Mikhailidis DP, Khan MA, Milionis HJ, Morgan RJ. The treatment of hypertension in patient with erectile dysfunction. Curr. Med. Res. Opin. 2000; 16 (suppl.1): 31-36

31. Penson DF. Erectile Dysfunction in Diabetic Patients. Diabetes Spectrum. 2004; 17:225-230. 